\title{
LETTER
}

\section{Dobutamine administration in patients after cardiac surgery: beneficial or harmful?}

\author{
Ludhmila A Hajjar*, Julia T Fukushima, Eduardo Osawa, Juliano P Almeida and Filomena RBG Galas \\ See related research by Shahin et al., http://ccforum.com/content/15/4/R162
}

We read with interest the article by Shahin and colleagues [1] in the previous issue of Critical Care. The authors suggested, in a retrospective analysis, that dobutamine use in patients undergoing cardiac surgery was independently associated with a 2.3 -fold increase in mortality and a 2.7 -fold increase in risk of renal dysfunction. We have some concerns regarding this conclusion. The primary concern with this analysis is the choice of covariates included in the multivariable logistic regression. These were not derived from a univariate analysis. Also, co-variates included in the logistic regression were different from variables used in the matching propensity analysis. In the matching analysis, the ejection fraction (EF) in the group exposed to dobutamine was significantly lower than the EF in the other patients, and this may have contributed to worse outcomes. So, these potential biases are of concern, especially when we consider that these results are inconsistent with the daily routine practice of cardiac surgery in many centers.
In a recent commentary, Singer and Brealey [2] argued that, other than dobutamine, current options to improve the hemodynamic status of critically ill patients are relatively limited. After cardiac surgery, this is even more true, as the vasodilation frequently present in these patients can limit the use of other inodilators like levosimendan and milrinone [3]. Pharmacological support for low cardiac output is often required during and after weaning from cardiopulmonary bypass [4]. During this early postoperative period, optimization of cardiac output is needed to prevent complications, and dobutamine is the drug of choice because of its good tolerance and safety [5].

New agents are being evaluated, but dobutamine is still the inotropic of choice in patients undergoing cardiac surgery [4]. Although this study suggests that dobutamine may increase morbidity and mortality after cardiac surgery [1], there is no reason to ban dobutamine after cardiac surgery, as it may still be more beneficial than harmful.

\section{Author's response}

Jason Shahin

We thank Hajjar and colleagues for their interest in our article examining the association between inotrope exposure and poor outcomes in a cardiac surgery population. In regard to the choice of co-variates in the multivariable model, we choose to include variables that were known $a$ priori (that is, on the basis of previous literature and clinical expertise) to have an association with mortality and renal failure. We have concerns with the common practice of choosing co-variates on the basis of univariable analysis, as the potential for bias exists [6]. Specifically, variables can be inappropriately excluded

*Correspondence: ludhmila@usp.br

Surgical Intensive Care Unit, InCor, Heart Institute, University of Sao Paulo, Avenida Dr Eneas de Carvalho Aguiar no. 44, ZIP 05403-000, Sao Paulo, SP Brazil from a model if the prespecified $P$ value is not met in univariable analysis. As univariable analysis does not account for confounding, variables may be inappropriately excluded, leading to errors in the model [7].

With reference to the EF in the matched analysis, we agree that there were small differences in the mean EF. However, given that there was a similar proportion of patients with an EF of less than 30\% (Table 5 in [1]), the potential for bias is minimal. This difference is unlikely to account for the observed association between inotrope exposure and mortality.

We also agree that there is no reason to 'ban dobutamine after cardiac surgery', as it is an important medication in our clinical armamentarium. Our data did not suggest that one inotrope was worse than the other. In fact, only $14 \%$ of admissions in the inotrope-exposed group received postoperative dobutamine. Rather than a 
ban on inotropes, what is required is a more judicious and evidence-based approach to their use given their potential for harm.

\section{Abbreviation}

$\mathrm{EF}$, ejection fraction.

\section{Competing interests}

The authors declare that they have no competing interests.

Published: 27 September 2011

\section{References}

1. Shahin J, deVarennes B, Wing Tse C, Amarica DA, Dial S: The relationship between inotrope exposure, six-hour physiological variables, and hospital mortality and renal dysfunction in patients undergoing cardiac surgery. Crit Care 2011, 15:R162.

2. Singer M, Brealey D: Another nail in the hammer's coffin? Crit Care 2011, 15:179.
3. Feneck RO, Sherry KM, Withington PS, Oduro-Dominah A: Comparison of the haemodynamic effects of milrinone with dobutamine in patients after cardiac surgery. J Cardiothoracic Vasc Anesth 2001, 15:306-315.

4. Gillies M, Bellomo R, Doolan L, Buxton B: Bench-to-bedside review: Inotropic drug therapy after adult cardiac surgery - a systematic literature review. Crit Care 2005, 9:266-279.

5. Polonen P, Ruokonen E, Hippelainen M, Poyhonen M, Takala J: A prospective, randomized study of goal-oriented hemodynamic therapy in cardiac surgical patients. Anesth Analg 2000, 90:1052-1059.

6. Mallett S, Royston P, Dutton S, Waters R, Altman DG: Reporting methods in studies developing prognostic models in cancer: a review. BMC Med 2010, 8:20.

7. Guo-Wen S, Shook LT, Kay GL: Inappropriate use of bivariable analysis to screen risk factors for use in multivariable analysis. J Clin Epidemiol 1996, 49:907-916.

doi:10.1186/cc10439

Cite this article as: Hajjar LA, et al.: Dobutamine administration in patients after cardiac surgery: beneficial or harmful? Critical Care 2011, 15:444. 